\title{
A NARROW HYBRID ZONE BETWEEN TWO WESTERN AUSTRALIAN FROG SPECIES RANIDELLA INSIGNIFERA AND $R$. PSEUDINSIGNIFERA: THE FITNESS OF HYBRIDS
}

\author{
C. MICHAEL BULL* \\ Department of Zoology, University of Western Australia, Nedlands, Western Australia
}

Received 7.xii.78

\begin{abstract}
SUMmary
The mechanisms which maintain the stable narrow hybrid zone between Ranidella insignifera and $R$. pseudinsignifera are not clear. To test the hypothesis that reduced hybrid fitness is a factor preventing gene flow through the hybrid zone, a number of experimental interspecific hybrid crosses were performed. There was no indication that hybrid progeny had lower survival than those from control conspecific crosses at any stage from egg to metamorphosis. Nor was there any evidence for hybrid sterility. Alternative hypotheses to account for the narrow hybrid zone are discussed including superior hybrid fitness at an ecotone and decreased hybrid fitness as a consequence of not being able to find a mate.
\end{abstract}

\section{INTRODUCTION}

Stable narrow hybrid zones between related taxa are now well known. Two theories have arisen to account for their persistence. One, originally proposed by Anderson (1948), suggests that a hybrid zone is located at an ecotone between the habitat preferred by one taxon and that preferred by the other. If intermediate habitats are found in the ecotone, then hybrids, with part of their genome adapted to each habitat, might be fitter there than either parental taxon. The theory predicts that hybrids have heterotic fitness within the ecotone, but reduced fitness in either of the habitats outside the ecotone where one or the other parental taxon is better adapted. Moore (1977) has suggested that this hybrid superiority maintains many hybrid zones between vertebrates. Hagen (1967) and Littlejohn and Watson (1973) use it to explain specific cases of narrow hybrid zones.

The second theory suggests that hybrids formed at the secondary contact of related taxa have reduced fitness as a consequence of the breakdown of the parental genomes. This would restrict gene flow across the contact beyond a hybrid zone if intertaxon mating takes place. Dobzhansky (1970) suggested that hybrid zones would be transient because reinforcement of reproductive isolating barriers might lead to assortative mating and reduced hybrid production at the contact. Loftus-Hills (1975) has pointed out that reinforcement is not commonly known in natural situations, perhaps because of the continual swamping of hybrid zone populations by parental individuals from allopatric populations outside of the influence of the selective pressure for reinforcement (Littlejohn, 1969; Watson, 1972).

The continual production of hybrids with reduced fitness has been used

* Present address: School of Biological Sciences, Flinders University, Bedford Park, South Australia 5042. 
to explain the persistence of several stable hybrid zones (Watson, Loftus-Hills and Littlejohn, 1971; Hall and Selander 1973). Both models predict that there is a difference in fitness between hybrids and their parental taxa in the region of the hybrid zone. The first model suggests that hybrids will be fitter, the second that they will be less fit than either parental form. It should be possible to differentiate between these hypotheses in specific cases.

One hybrid zone in which the mechanism of maintenance remains to be explained is that between the frog species Ranidella insignifera and $R$. pseudinsignifera in Western Australia. These two sibling species were first detected by differences in the male mating call (Main, 1957). Their allopatric distributions abut along a long common boundary (Littlejohn, 1959), with areas of narrow contact zones containing intermediate and parental calls (Littlejohn, 1959, Bull, 1978) and abrupt changes in electrophoretic and morphological characters (Blackwell and Bull, 1978). The position and width of one such zone has remained stable for at least 19 years (Bull, 1978). These observations suggest that the stable narrow hybrid zone lies between two taxa which have several genetical differences. Either of the two hypotheses might account for the persistence of the zone. On the one hand, the zone coincides with the scarp of the low Darling Ranges (Littlejohn, 1959; Bull, 1978). R. insignifera is confined to the coastal plains and $R$. pseudinsignifera predominantly occupies the inland plateau. The environmental change at the base of the escarpment where the species contact might represent an ecotone where hybrids have superior fitness. On the other hand, Main (1968) reported reduced survival to hatching of eggs from crosses between the two species, and sterility of four males with aberrant call types from the hybrid zone, supporting the model of reduced hybrid success at the zone.

Critical assessment of these alternatives is difficult because data are only available from two controlled crosses between the species (Littlejohn, 1957), in both of which the hybrid progeny survived as well to hatching as the parental forms. This paper reports a more substantial investigation into the fitness of laboratory-raised hybrids between the two species, and an attempt to discriminate between the two hypotheses. If hybrids are shown to have a reduced fitness in early growth, or if hybrid adults are shown to be sterile, then there would be strong arguments in support of the reduced hybrid fitness model, and against the model of hybrid heterosis.

\section{MATERIALS AND METHOdS}

Adult frogs were taken from allopatric populations, and from populations in the hybrid zone. Precise locations have been previously given (Bull, 1977, 1978). Crosses were made by the method of Watson (1977). Sperm suspensions were made from males of two different populations. About half of the eggs of a female from one of these populations were placed in each suspension. Thus eggs from each female were used in both an experimental interpopulation cross and a control within-population cross. The eggs were kept in finger-bowls and checked daily until hatching was completed. Those embryos which did not develop normally were removed to prevent contamination. Hatched tadpoles from some crosses were transferred to round plastic bowls (diameter $35 \mathrm{~cm}$ : capacity $3.5 \mathrm{l}$ ) and kept in a shaded area outdoors. The tadpoles browsed on the natural algal growth 
on the sides of the bowls. At two week intervals the growth and survival of tadpoles was determined until all had metamorphosed. Initially, each bowl contained 20 or 30 newly hatched tadpoles. Tadpoles from interpopulation crosses, and their controls from the same female, were kept in adjacent bowls.

Metamorphosed hybrids, toe-clipped for identification, were transferred to an enclosed artificial pond. Adult males from this pond were used in experimental backcrosses during the following winter. Although mature adult hybrid females were present, none was found with eggs descended into the ovisacs ready for fertilisation. (It was common to find unclasped females of the parental species in the same condition as the hybrid females.) Other backcrosses were made by using males from a natural population within the hybrid zone which were subjectively identified as hybrids by their mating call.

\section{RESUlts}

\section{(a) F1 hybrid crosses}

\section{(i) Survival to hatching}

The results of 54 controlled crosses between $R$. insignifera females and $R$. pseudinsignifera males from allopatric populations are summarised in table 1. Fertilisation rates were high and no significant differences were found between control and experimental batches in 40 ( 74 per cent) pairs. Among the remaining 14 pairs, 10 (71 per cent) showed significantly higher fertilisation rates in the experimental interspecies batches than in the controls. No significant difference was found $\left(T_{\mathrm{s}}=544.5 ; t_{54}=1 \cdot 70\right.$ : n.s.) between percentage fertilisation in control and experimental groups using a Wilcoxon signed rank test (Sokal and RohIf, 1969).

In 40 ( 74 per cent) of the crosses there was no difference between control and experimental batches in the success of fertilised eggs reaching hatching. In 9 of the 14 crosses where differences were significant experimental interspecific crosses performed better than controls. Over all 54 crosses the Wilcoxon signed rank test showed a trend (which was not quite significant at the 5 per cent level) for higher success in interspecific batches relative to their controls $\left(T_{\mathrm{s}}=515.5 ; \mathrm{t}_{54}=1.95 ; \mathrm{P}<0 \cdot 1\right)$.

Table 1 also summarises 40 controlled crosses between $R$. pseudinsignifera females and $R$. insignifera males from allopatric populations. Fertilisation success was high and in 31 ( 78 per cent) cases there was no significant difference between control and experimental batches. In the remaining nine crosses significantly higher proportions of eggs were fertilised in the experimental interspecific batches than in the controls. The Wilcoxon signed rank test for all 40 crosses showed that experimental batches had significantly higher fertilisation success than their controls $\left(T_{\mathrm{s}}=225\right.$; $\mathrm{P}<0.01$ ). (In this test a Student's $t$ value is only derived for samples greater than 50.)

Thirty (75 per cent) pairs of crosses showed no significant difference between control and experimental batches in the proportion of fertilised eggs which hatched. Among those where there was a significant difference nine (90 per cent) had a higher proportion of the experimental batch hatching than its control. The Wilcoxon signed rank test for all 40 crosses showed significantly higher proportions hatching in the experimental batches compared to their controls $\left(\mathrm{T}_{\mathrm{s}}=208 ; \mathrm{P}<0.005\right)$. 
TABLE 1

Summary of the results from egg to hatching in sets of laboratory crosses and their controls. In F1 crosses allopatric populations are indicated in the following manner-R. insignifera populations: WW-William Welshpool Road; TH-Thornlie; EB-Ellen Brook; VP-Victoria Parade. R. pseudinsignifera populations; PB-Pickering Brook; JS-Jacoby St.; CR-Charles Rd.; GF-Glen Forrest; WB-Wandena Bog; EG-East of Gingin T.O.

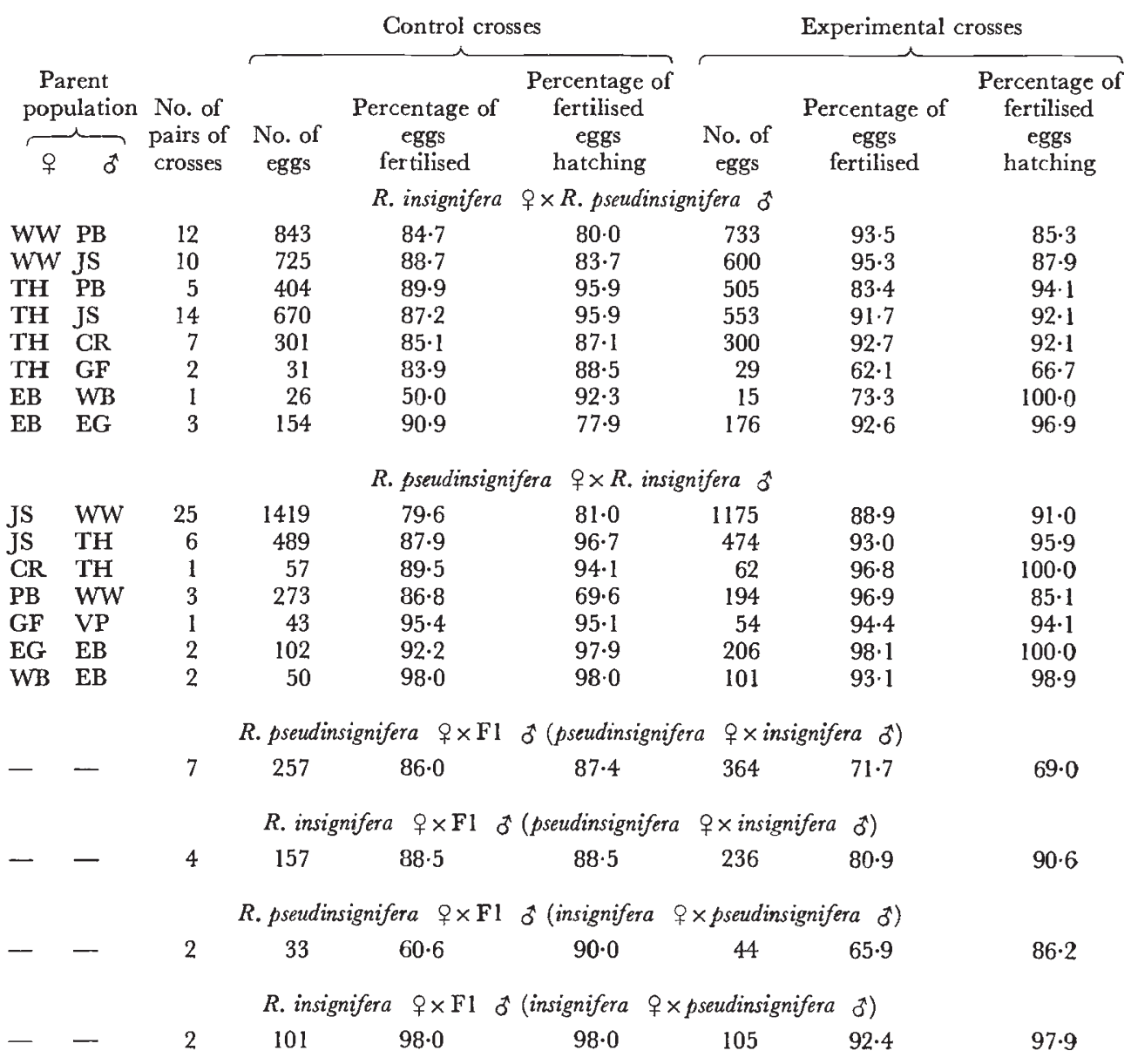

\section{(b) Backcrosses}

The results of 15 backcrosses involving laboratory raised hybrid males and wild-caught parental females are summarised in table 1. Individual backcrosses, when compared with their controls, gave no indication that hybrid males were sterile or that there was reduced viability of their offspring. In 12 crosses fertilisation success was as high in control as in experimental batches. In the remaining three crosses the experimental batches had significantly lower fertilisation success. In 13 pairs of crosses there was no significant difference between control and experimental batches in the proportion of fertilised eggs which hatched. The control batch had a significantly higher proportion hatching in one, and the experimental batch in the other of the two remaining crosses. The Wilcoxon 
signed rank test showed no significant difference between control and experimental batches for the 15 crosses for either level of fertilisation $\left(\mathrm{T}_{\mathrm{s}}=\right.$ 37 ; n.s.) or survival to hatching of fertilised eggs $\left(T_{s}=52 ; n . s.\right)$.

These data were supplemented by crossing three field-caught males with subjectively determined hybrid call types from the Wilkie-Coulston Road population, to a female from the same site. The three egg batches had an average 78.9 per cent fertilisation, and an average 88.5 per cent of fertilised eggs hatched. The control cross between this female and a male $R$. pseudinsignifera from Jacoby Street had 80 per cent fertilisation and 83.3 per cent hatching. The results gave no indication of sterility in hybrid males.

Clasped females from populations previously assessed (Blackwell and Bull, 1978; Bull, 1978) to contain high proportions of hybrid males (Helena Valley Gutter Creek, Wilkie-Coulston Road) produced viable eggs with high levels of survival to hatching (Bull, 1973), but the identity of the females could not be ascertained. Tadpoles were found in one of the raising ponds which contained only Fl hybrid adults, implying that Fl hybrid females can produce viable offspring.

\section{(c) Other crosses}

Females from allopatric populations were crossed to males from populations on the opposite edge of the hybrid zone. Electrophoretic data (Blackwell and Bull, 1978) and acoustic data (Bull, 1978) suggest that these latter populations consisted predominantly of one parental species with some hybrids. Thus most of the crosses would have produced Fl hybrid progeny and some backcross progeny.

Of 20 controlled crosses between $R$. insignifera females from Thornlie and from William-Welshpool Road and hybrid zone males from Hale Road and Boya, three showed significant differences in levels of fertilisation (two with experimentals exceeding controls), and three showed significant differences in survival to hatching of fertilised eggs (two with controls exceeding experimentals). Wilcoxon signed rank tests showed no significant difference between control groups and experimental groups over the whole 20 crosses for either level of fertilisation ( $\mathrm{T}_{\mathrm{s}}=87.5$; n.s.) or for survival to hatching $\left(\mathrm{T}_{\mathrm{s}}=100 ;\right.$ n.s. $)$.

In 24 controlled crosses between $R$. pseudinsignifera females from Charles Road, Jacoby Street and Glen Forrest and hybrid zone males from HartfieldLewis Road, First Dip Helena Valley Road and Gravel Pit Helena Valley Road (the latter three localities being on the $R$. insignifera edge of the hybrid zone), three showed significant differences in level of fertilisation (two with controls exceeding experimentals) and five showed significant differences in the survival to hatching of fertilised eggs (three with controls exceeding experimentals). Wilcoxon signed rank tests showed no significant difference between controls and experimentals for all 24 crosses for either level of fertilisation ( $T_{\mathrm{s}}=125.5$; n.s.) or for survival to hatching of fertilised eggs $\left(\mathrm{T}_{\mathrm{s}}=129 ;\right.$ n.s. $)$.

(ii) Survival from hatching to metamorphosis

\section{(a) F1 hybrid crosses}

Table 2 summarises the survival until metamorphosis, of tadpole from sets of crosses between allopatric populations of the two species compared 
TABLE 2

Summary of the percentages of tadpoles reaching metamorphosis in sets of laboratory crosses and their controls

\begin{tabular}{|c|c|c|c|c|}
\hline \multirow{2}{*}{$\begin{array}{l}\text { No. of } \\
\text { pairs of } \\
\text { crosses }\end{array}$} & \multicolumn{2}{|r|}{ Control crosses } & \multicolumn{2}{|c|}{ Experimental crosses } \\
\hline & $\begin{array}{l}\text { No. of } \\
\text { tadpoles }\end{array}$ & $\begin{array}{c}\text { Percent } \\
\text { metamorphosing }\end{array}$ & $\begin{array}{l}\text { No. of } \\
\text { tadpoles }\end{array}$ & $\begin{array}{c}\text { Percent } \\
\text { metamorphosing }\end{array}$ \\
\hline \multicolumn{5}{|c|}{$R$. insignifera $\$ \times R$. pseudinsignifera 0} \\
\hline 11 & 314 & $46 \cdot 2$ & 290 & $40 \cdot 7$ \\
\hline \multicolumn{5}{|c|}{ R. pseudinsignifera $q \times R$. insignifera $\circlearrowleft$} \\
\hline 13 & 353 & $35 \cdot 7$ & 363 & $30 \cdot 0$ \\
\hline \multirow{3}{*}{5} & R. pseudinsignifera & $a \quad q \times \mathrm{F} 1 \quad \tilde{\sigma}$ (pseudinsigni & fera o $\times$ insign & $\left.a \sigma^{\pi}\right)$ \\
\hline & 112 & $28 \cdot 6$ & 108 & $41 \cdot 7$ \\
\hline & R. insignifera & O $\times \mathrm{F} 1 \quad \delta^{*}$ (pseudinsignifer & a $q \times$ insignifer & ठ) \\
\hline \multirow[t]{2}{*}{2} & 90 & $34 \cdot 4$ & 90 & $43 \cdot 3$ \\
\hline & R. pseudinsignifera & a + $\times \mathrm{F} 1 \quad \widehat{o}$ (insignifera & $q \times p$ seudinsigni & $\left.a \delta^{*}\right)$ \\
\hline \multirow[t]{2}{*}{2} & 18 & $72 \cdot 2$ & 25 & $60 \cdot 0$ \\
\hline & R. insignifera & $+\times \mathrm{Fl}$ ठै (insignifera q & $\times$ pseudinsignifer & ठ) \\
\hline 2 & 56 & $51 \cdot 8$ & 79 & $43 \cdot 0$ \\
\hline
\end{tabular}

to their controls. Some crosses showed significant differences between control groups and experimental groups (in four cases the experimentals having higher survival, and in two cases the controls), but there was no indication that either group was consistently more successful. Wilcoxon signed rank tests showed no differences in the 11 crosses to $R$. insignifera females $\left(\mathrm{T}_{\mathrm{s}}=30.5 ; \mathrm{n} . \mathrm{s}\right.$. $)$, in the 13 crosses to $R$. pseudinsignifera females $\left(\mathrm{T}_{\mathrm{s}}=23\right.$; n.s. $)$ or in the pooled sample of 24 interspecies crosses $\left(\mathrm{T}_{\mathrm{s}}=128\right.$; n.s.).

\section{(b) Backcrosses}

Table 2 shows the survival of tadpoles to metamorphosis in 11 backcrosses to hybrid males. Individual crosses showed variable success relative to their controls. In three cases backcrosses had significantly higher survival, and in one the control did, but there was no significant trend, either among those pairs that did show significant differences, or in the whole sample (Wilcoxon signed rank test, $\mathrm{T}_{\mathrm{s}}=33$; n.s.).

\section{(c) Other crosses}

Progeny of nine of the crosses between $R$. insignifera females and males from the $R$. pseudinsignifera edge of the hybrid zone were raised to metamorphosis. Two were significantly different from their controls, one having higher and the other lower survival. In 11 crosses between $R$. pseudinsignifera females and males from the $R$. insignifera edge of the hybrid zone the survival to metamorphosis was not significantly different from controls in eight cases, was greater than controls in two cases and was lower than 
controls in one case. Wilcoxon signed rank tests showed no overall differences for each of the two samples $\left(T_{B}=17\right.$; n.s. and $T_{B}=30.5$; n.s.) nor for the pooled sample of 20 crosses $\left(T_{B}=99\right.$; n.s.).

\section{Discussion}

The experimental data can now be examined in the light of the hypothesis that the stable narrow hybrid zone is maintained by the reduced fitness of hybrids produced by parental individuals which have migrated into the zone and mismated. The data from this study show no evidence of hybrid disadvantage related to intrinsic genetical incompatibility between the two species. Hybrid crosses were equal to or better than parental control crosses in the proportions successfully developing in all stages from egg to metamorphosis. An earlier analysis (Bull, 1977) showed no differences between the two species or their hybrids in the time to reach metamorphosis. The size and wet weight of metamorphosing hybrids was intermediate between the two parental species. Laboratory raised hybrid males, intermediate calling males from a hybrid zone population, and other males from within the hybrid zone, all were as fertile as control males and eggs fertilised by these males developed as normally as those fertilised by control males. Indirect evidence suggested hybrid females produce viable eggs. In summary, hybrids do not show reduced fitness in terms of survival and growth in laboratory conditions, nor is there any indication of infertility in hybrid adults. Thus the hypothesis that reduced hybrid fitness results from interspecific genomic incompatibility is not supported by the experimental data.

The alternative hypothesis is that hybrids have superior fitness within an ecotone at the common boundary. Clearly the laboratory is not the site to test this hypothesis. It is not necessarily supported by the demonstration of hybrid vigour from egg to hatching in laboratory containers, because the model predicts reduced hybrid fitness in all but the intermediate habitats of the ecotone. Furthermore it is not clear that there is an ecotone at the common boundary.

The hybrid zone coincides with a low escarpment, but there are no obvious major changes in macroclimate, vegetation, pond properties (Bull, 1973, 1978) or soil type (Burbridge, 1963). The scarp may act as a physical barrier reducing migration by $R$. insignifera out of the coastal plain, but there is no obvious change in habitat which would prevent $R$. pseudinsignifera from migrating on to the plain. Nevertheless the hypothesis should be tested by measuring relative survival of the two species and their hybrids at different sites across the zone.

Despite the results of this study there are two ways that reduced hybrid fitness may play a part in maintaining the hybrid zone. Firstly the fitness in laboratory containers may be quite irrelevant to the relative survival of hybrid and parental individuals in natural populations. There may be incompatibilities between the genomes of the species such that hybrids are not as well adapted to all the environmental stresses that they must face. Alternatively, hybrids may survive as well as the parental species but have lowered fitness because male hybrids with intermediate calls cannot attract mates. One case is known where calls of hybrid males attracted female frogs of the two parental species as well as the calls of the parental species (Littlejohn and Watson, 1976), but in other anuran species, females are 
highly selective of the male they choose to mate with from within a chorus (Licht, 1976; Wells, 1977). Females of other species of frogs and crickets discriminate against hybrid calls when calls of parental species are offered as an alternative (Hoy and Paul, 1973; Gerhardt, 1974). This factor may reduce the reproductive success of hybrids sufficiently to prevent introgression proceeding beyond the hybrid zone. These various models still need to be tested experimentally, but this paper eliminates one simple hypothesis, that the maintenance of the stable narrow hybrid zone can be explained by a reduced hybrid fitness resulting from major genetic incompatibilities between the two species.

Acknowledgments.-This work was carried out under the supervision of Professors A. R. Main and H. E. Paterson while the author held a Commonwealth Postgraduate Research Award at the University of Western Australia. During the project help was also given by J. Bull and Dr J. Blackwell. Useful comments on the manuscript were given by R. Andrews, N. Barton, Dr G. Hewitt, Dr M. Littlejohn and Dr G. Watson.

\section{REFERENCES}

ANDERSON, E. 1948. Hybridization of the habitat. Evolution 2, 1-9.

BLACKWELL, J. M., AND BULL, C. M. 1978. A narrow hybrid zone between two Western Australian frog species Ranidella insignifera and $R$. pseudinsignifera: the extent of introgression. Heredity, 40, 13-25.

BULL, C. M. 1973. The interactions of two allopatric frog species at their common boundary. Ph.D. thesis, University of Western Australia.

BULL, C. M. 1977. Back pattern polymorphism and tadpole growth rate in two Western Australian frogs. Aust. J. Zool., 25, 243-248.

Bull, c. M. 1978. The position and stability of a hybrid zone between the Western Australian frogs Ranidella insignifera and $R$. pseudinsignifera. Aust. J. Zool., 26, 305-322.

BURBridge, A. A. 1963. The relationships of Crinia insignifera Moore and Crinia pseudinsignifera Main in a region of sympatry at Bullsbrook. Unpublished B.Sc. Honours thesis, Zoology Department, University of Western Australia.

Dobzhansky, T. 1970. Genetics of the Evolutionary Process. Columbia University Press, New York.

GERHARDT, H. C. 1974. The vocalizations of some hybrid tree frogs: acoustic and behavioural analyses. Behaviour, 49, 130-151.

HAGEN, D. W. 1967. Isolating mechanisms in three-spined sticklebacks (Gasterosteus). 7. Fish. Res. Bd. Canada, 24, 1637-1692.

HALL, W. P., AND SELANDER, R. K. 1973. Hybridization of karyotypically differentiated populations in the Sceloporus grammicus complex (Iguanidae). Evolution, 27, 226-242.

HOY, R. R., AND PAUL, R. C. 1973. Genetic control of song specificity in crickets. Science, $180,82-83$.

LiCht, L. E. 1976. Sexual selection in toads Bufo americanus. Can. F. Zool., 54, 1277-1284.

Littlejohn, м. J. 1957. The biology of the genus Crinia Tschudi. Ph.D. Thesis, University of Western Australia.

LitTLEJohn, M. J. 1959. Call differentiation in a complex of seven species of Crinia (Anura : Leptodactylidae). Evolution, 13, 452-468.

Littlejohn, м. J. 1969. The systematic significance of isolating mechanisms. In Systematic Biology, ed. C. S. Sibley. National Academy of Sciences, Washington, D.C.

LitTLEJOHN, M. J., AND WATSON, G. F. 1973. Mating call variation across a narrow hybrid zone between Crinia laevis and C. victoriana. Aust. 7. Zool., 21, 277-284.

LitTLEJOHN, M. J., AND WATSON, G. F. 1976. Effectiveness of a hybrid mating call in eliciting phonotaxis by females of the Geocrinia laevis complex (Anura : Leptodactylidae). Copeia, 1976, 76-79.

LofTUS-Hills, J. J. 1975. The evidence for reproductive character displacement between the toads Bufo americanus and B. woodhousii fowleri. Evolution, 29, 368-369.

MaIN, A. R. 1957. Studies of Australian amphibia. I. The genus Crinia Tschudi in southwestern Australia and some species from south-eastern Australia. Aust. J. Zool., 5, 30-55. 
MOORE, w. s. 1977. An evaluation of narrow hybrid zones in vertebrates. Q. Rev. Biol., 52, 263-277.

SOKAL, R. R., AND ROHLF, F. J. 1969. Biometry. W. H. Freeman \& Co., San Francisco.

WATson, G. F. 1972. The Litoria ewingi complex (Anura : Hylidae) in south-eastern Australia. II. Genetic incompatibility and delimitation of a narrow hybrid zone between $L$. ewingi and $L$. paraewingi. Aust. F. Zool., 20, 423-433.

watson, G. F. 1977. Artificial hybridization techniques for anuran amphibians. Aust. Zoologist, 19, 239-241.

WAtson, G. F., LOFTUS-hills, J. J., AND LitTlejohn, M. J. 1971. The Litoria ewingi complex (Anura : Hylidae) in south-eastern Australia. I. A new species from Victoria. Aust. 7. Zool., 19, 401-416.

WELLS, K. D. 1977. Territoriality and male mating success in the green frog (Rana clamitans). Ecology, 58, 750-762. 